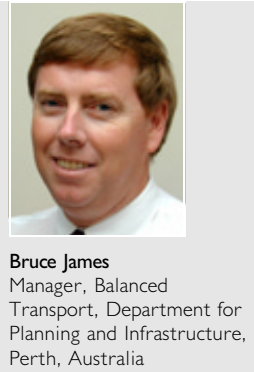

\title{
TravelSmart_-large-scale cost-effective mobility management. Experiences from Perth, Western Australia
}

\section{B. James}

Travel demand management or mobility management is growing in interest as political decision-makers realise that it is not financially and socially feasible to attempt to build enough roads to satisfy growing car use. In reaching this conclusion, political decision-makers confront a dilemma. Car users want quicker travel times for their car trips but they are not prepared to suffer the negative impacts of excessive car use. The solution lies in changing the travel behaviour of individuals but not through measures that are seen to constrain current car use. Therefore low-cost voluntary behaviour change programmes that deliver change are very appealing. The implementation of the Western Australian large scale TravelSmart programme proves that it is possible to motivate people to use their cars less without constraining access to their destinations. The outcome is a very cost-effective alternative to building expensive road infrastructure solutions and provides better use of public transport, cycling and walking infrastructure. The programme has been able to achieve a modal split which parallels that of the early 1980s and the planned programme will be implemented on a large scale reaching over 300000 people. This programme provides a way forward in a field of transport that has been bereft of effective techniques acceptable to political decision-makers. The winning of resources for the programme has been undertaken within a 'campaign' framework comprising proof of public value, developing a capacity to deliver, and winning community support. TravelSmart has developed from an extensive knowledge of travel behaviour and applied within a leadership and community learning paradigm.

\section{INTRODUCTION}

Travel demand management or mobility management has developed in recent times from concepts to reality as the political and community imperative has demanded transport professionals achieve desired transport outcomes in a costeffective way. Community expectations for comprehensive solutions rather than the traditional single-sector solutions have precipitated a paradigm change for many transport planners.

This paper outlines the transport planner driven approach taken in Perth, Western Australia, to address these expectations. The focus has been on volunteer travel behaviour change and delivered within a 'campaign' framework to attract sufficient resources to mainstream the flagship programme, TravelSmart Individualised Marketing. The framework and the principles applied within the framework are described and supported with evidence where appropriate.

The outcome achieved is a major reduction in car driver trips with a commensurate increase in walking, cycling and public transport trips for a large proportion of the Perth population. The funding of the programme from capital funds, within a strategic asset management decision process, allows comparison with a traditional transport infrastructure projects and the cost-effectiveness of the programme means it is able to attract sufficient resources.

An outline of how Individualised Marketing works is presented along with the results of the pilot project and the first largescale application. A brief description is also provided of the other programmes operating within the TravelSmart suite of initiatives.

A more detailed description of the TravelSmart activities and tools, such as the cost-benefit analysis, is available on the website at www.travelsmart.transport.wa.gov.au.

\section{WHAT IS TRAVELSMART AND WHY DO IT?}

TravelSmart ${ }^{\mathbb{R}}$ is the registered trade mark attached to a suite of initiatives that entail voluntary travel behaviour change programmes in Western Australia. The aim of TravelSmart is to achieve desired targets defined in the Metropolitan Transport Strategy (MTS) for the Perth Metropolitan Region, as shown in Fig. $1 .^{1}$ It achieves this reduction in the number of car trips people make by empowering them to walk, cycle and use public transport. The emphasis is on voluntary behaviour change as opposed to involuntary change through measures such as road pricing or parking restraints.

The reason for these targets is to retain the liveable city features of Perth over the next 30 years as the population grows by $25 \%$. The growth in vehicle-kilometres is forecast to increase by $50 \%$.

The evidence collected and presented in this paper shows that TravelSmart is able to make a substantial yet cost-effective contribution to achieving these targets. 


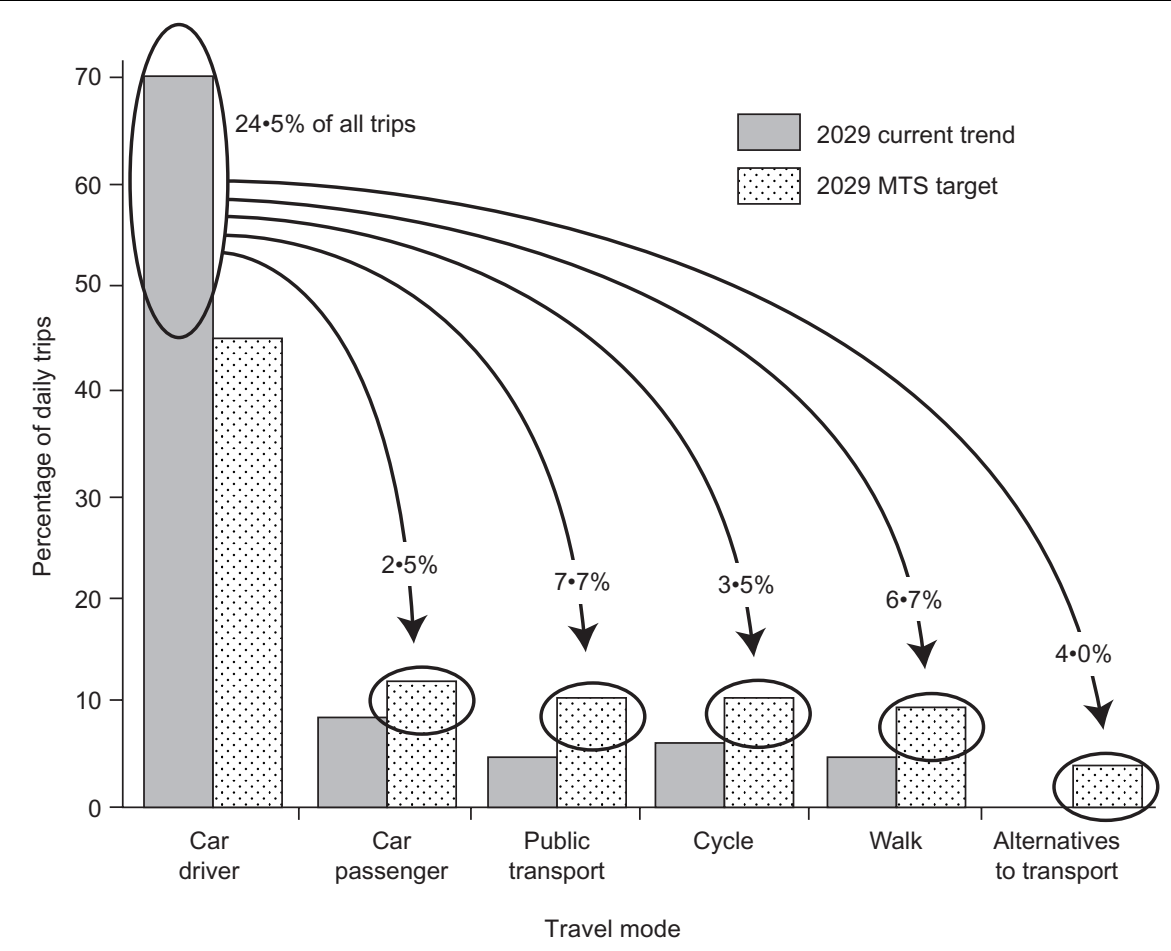

Fig. I. Modal split targets defined in the Metropolitan Transport Strategy

\section{TRAVELSMART PRINCIPLES}

The principles applied to win resources for TravelSmart are based around the need to achieve confluence of three factors, as defined by Professor Hermann 'Dutch' Leonard. ${ }^{2}$ As shown in Fig. 2, the factors are

(a) quantification of public value of the programme to the community, Government and private sector

(b) gathering community support

(c) building capacity to deliver the programme.

Within these three factors, the principles used are now described.

\section{I. Public value}

The method used to quantify public value is to measure actual behaviour change. From this it is possible to estimate benefits,

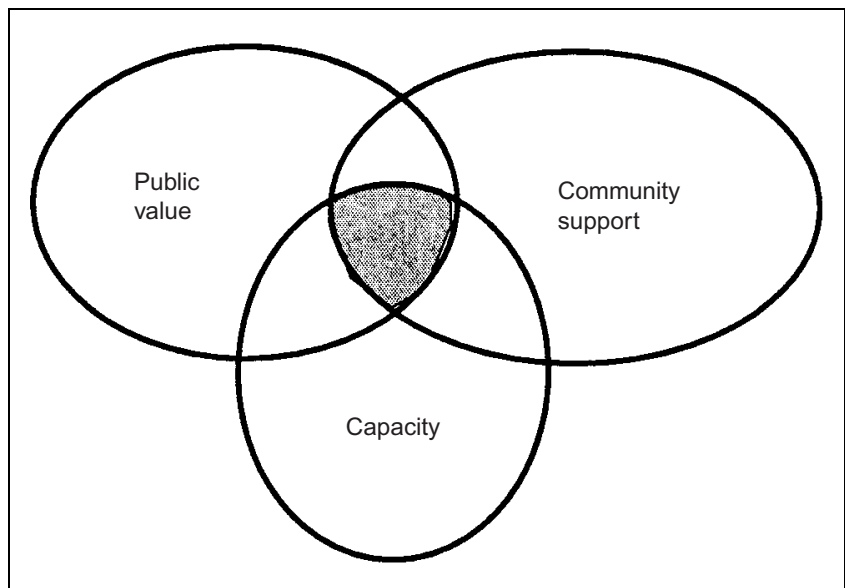

Fig. 2. The three underlying principles of TravelSmart such as the health benefits from increased physical activity from walking and cycling.

3.1.1. Measuring results. There are two fundamental questions that had to be answered to quantify public value.

(a) Will people change their behaviour and by how much?

(b) If they change their behaviour, how long will it last?

The rigorous measurement processes using 'before' and 'after' evaluation travel surveys with control groups and random sampling provided

(a) evidence that behaviour change is possible and is sustained

(b) arguments for behaviour change based on facts rather than theory or ideology

(c) quantification of the costs and benefits vital to obtain resources.

The measurement of change is essential to construct business cases for resources. The measure of success is the extent of people's behaviour change rather than differences in people's knowledge and attitudes. The other quantification has been the change in car use; the primary measure being changes in overall vehicle-kilometres travelled. This measure of change in people's travel behaviour and car use has been fundamental in attracting sufficient resources.

\subsection{Community support}

To build community support, a 'campaign' approach was adopted (the term 'campaign' being used in the context of influencing decision-makers and not in the sense of a social marketing campaign with mass media marketing). This necessitated the development and implementation of strategies aimed 
at key decision-makers, which ran concurrently with the collection of evidence as per the public value principle.

The key aspects of the campaign to build community support were use of appropriate language, evidenced argument derived from research, stakeholder empowerment and garnering intersectoral support.

\subsubsection{Language. The use of appropriate language is important} in building community support. The term 'travel demand management' or 'mobility management' is difficult to understand and the word 'management' implies constrained mobility.

The branding 'TravelSmart: it's how you get there that counts' was adopted to overcome this negative perception. This also translates travel demand management into lay person's language. It will not be used for regulation or other interventions that are likely to constrain mobility, thereby changing people's understanding of what the brand means.

3.2.2. Research. Research is fundamental to the whole TravelSmart approach. The objective of the research was to build arguments for change based on evidence. The two primary research instruments were household travel surveys, to measure behaviour before and after the interventions, and a face-to-face in-depth household survey to ascertain attitudes and perceptions and quantify the potential for behaviour change. The indepth surveys are of sub-samples of the household travel surveys.

The in-depth household surveys identified strong community support for programmes favouring more walking, cycling and public transport. This became a crucial starting point to enlist the interest of political decision-makers. Use of an in-depth research technique developed and applied by Socialdata Australia was able to quantify the theoretical potential for behaviour change. $^{3}$

The in-depth research was able to identify that for 55\% of trips (see Fig. 3), people had no option but to continue using either the motor car or environmentally friendly modes (walking, cycling and public transport). The reasons include having to carry luggage, lack of a driver's licence, or it is too far to walk.

Conversely, for the other $45 \%$ of trips, people had the option of

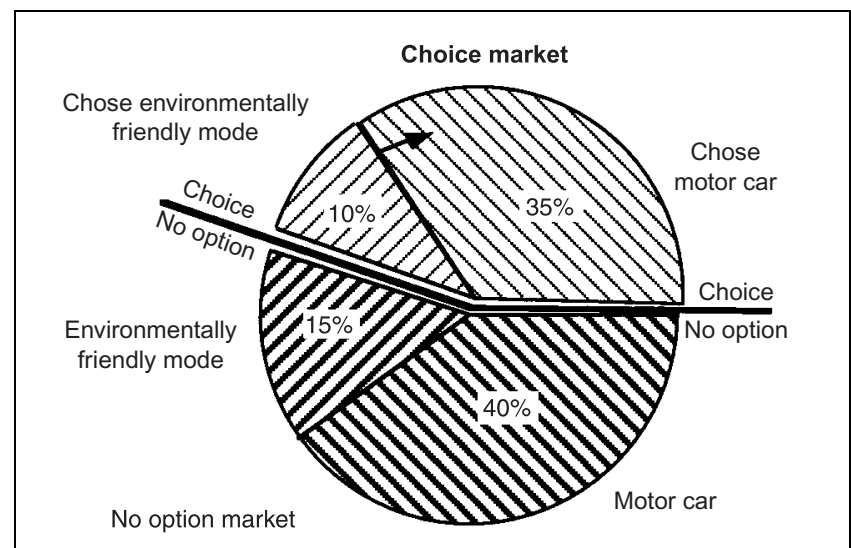

Fig. 3. The choice market and the no-option market using the environmentally friendly modes or using a motor car as a driver or passenger. The size of this 'choice market' is available without having to provide additional public transport services or cycling and walking infrastructure. In Perth they chose the motor car for 78\% of the 'choice market' trips. The objective of TravelSmart is to increase the choice market share for the environmentally friendly mode trips (as shown by the arrow in Fig. 3).

The key take-out message from this research is the debate shifts from whether people can change their behaviour to which technique to use. It also recognises that for many trips people have no option other than using their cars.

The combination of the measured results from Individualised Marketing with this potential research moved the debate in Perth from 'people will not get out of their cars' to identifying and applying effective voluntary behaviour change programmes that actually entice people to change car driver trips to other modes.

3.2.3. Empowerment. Principles of empowerment used entail concepts of community learning, partnerships and providing people with skills.

In the case of centralised programmes to deliver voluntary behaviour change, it is not about telling people to change but giving people the information, skills and motivation to choose the alternative modes to the car to suit their unique circumstances.

Empowerment is also important for agencies and organisations that will deliver their own TravelSmart programmes, such as local government and major trip attractors (e.g. universities and hospitals). The undertaking of travel research is combined with community learning processes for local government authorities to learn about travel behaviour of their local community and then implement initiatives relevant to their communities. The use of research for both community and agency empowerment underpins cultural change processes that occur within these organisations. This combination is also important for the community learning process with key opinion-leaders.

A key principle of the empowerment approach is for key opinion-leaders and decision-makers to realise that the sum of small travel behaviour changes each person makes delivers large effects. This results in

(a) people realising they do not have to sell their car or change their lifestyle

(b) empowering people so that they know they can contribute to the community good as well as gain personal benefits

(c) local opinion leaders learning that there are many realistic opportunities for people in their community to change car trips to walking, cycling and public transport trips.

3.2.4. Inter-sectoral support. Identification of the beneficiaries and building cross-sectoral support is important to any campaign. This was added by quantifying the benefits in the different sectors. A proactive strategy was implemented to expose the potential for and effectiveness of behaviour change techniques to the following sectors 
(a) public transport planners and providers

(b) cycling planners and advocates

(c) walking interests

(d) physical health advocates

(e) environmentalists

(f) road planners and advocates.

These stakeholders were shown the results of the research through a series of presentations over a couple of years following the completion of milestones in the pilot project and research. An example was a presentation made to politicians of all parties of how the project works, followed by a visit to the telephone room during the first large-scale Individualised Marketing project.

\subsection{Capacity}

Having the capacity to deliver programmes is as fundamental as having proven public value and built community support. Implementing travel behaviour change using voluntary measures is a new activity in the transport sector.

This has meant the need to pick and enhance proven programmes, such as Individualised Marketing developed in Germany for public transport and Safe Routes-to-School developed in the UK. These have been enhanced through continuous improvement after each application of the intervention.

The capacity issue is applicable not only for the Department for Planning and Infrastructure (DPI) but also for the private sector, local government and organisations responsible for managing major trip attractors. This also links closely to empowerment of these organisations.

\section{STRATEGIC ASSET MANAGEMENT}

The linkage between voluntary behaviour change and transport infrastructure in the DPI's resource allocation process is through the concept of strategic asset management (SAM). The application of the campaign paralleled the gaining of resources through the SAM process.

SAM is a decision process that considers a range of options before new physical infrastructure is constructed.

'In many circumstances it is possible, and desirable, for government to provide services without creating assets. Non-asset solutions may involve the rationalising of facilities, re-shaping community attitudes and demands, or changing the rules, for example, by altering legislation.' ${ }^{4}$

Proven TravelSmart programmes that deliver sustained behaviour change align with the definition of non-asset or non-built solutions.

Figure 4 shows the SAM decision-making process. The major infrastructure projects in the transport sector are roads, new public transport services, networks and stations, cycleways and footpaths. The first stage is to consider the effectiveness of nonbuilt solutions, or demand management options. In this case the aim of non-built solutions, in the context of the MTS targets, is to maximise the use of existing public transport, cycling and walking infrastructure and services and defer the demand for

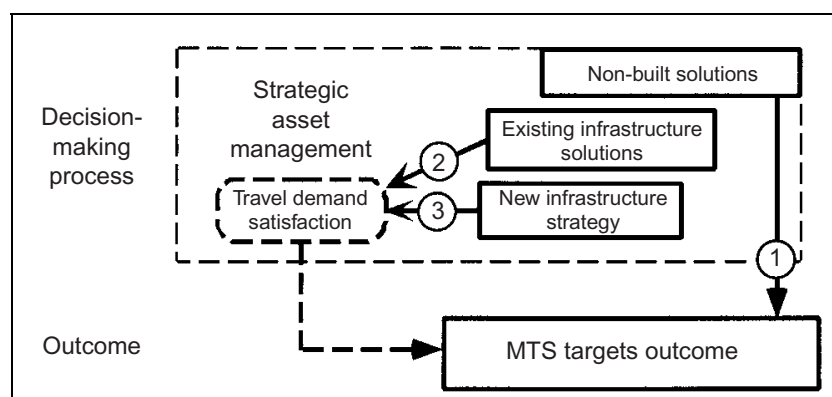

Fig. 4. Strategic asset management decision model

new road infrastructure. Having completed this stage, consideration is then given to modifying existing infrastructure to maximise its effectiveness in the second stage. The creation of new infrastructure to satisfy travel demand should only be considered when there are no cost-effective options available in the first and second stages.

The outcome of applying the SAM concept to TravelSmart is that it allows major TravelSmart programmes to be funded from capital funds. The capital funding process allows an annual assessment process of projects, a comparison between projects, and is much more lucrative than recurrent funding. The reason for this is that recurrent funding tends to remain fairly constant unless existing programmes are curtailed to accommodate new programmes. Institutionalised activities within large departments tend to make this a very difficult task. Therefore, funding for major new initiatives within the Western Australian public sector is best achieved from capital funding.

Establishing the conceptual rationale is one step; the next step is to prove the ability and cost-effectiveness of major TravelSmart projects to deliver outcomes. It has therefore been a crucial requirement to quantify the extent and sustainability of behaviour change achieved. Application of a cost-benefit assessment using this quantification allowed comparative judgements against other capital projects. Community support is also a crucial factor.

\section{TRAVELSMART INITIATIVES}

This section of the paper provides a description of the TravelSmart initiatives. It is worth reflecting on the various aspects within the campaign presented so far while reading this section. The development of initiatives under the TravelSmart brand can be categorised as follows.

(a) Centralised programmes delivered by the State Government. The two programmes delivered in this way are TravelSmart Individualised Marketing and TravelSmart Workplace.

(b) Empowerment of organisations to deliver their own TravelSmart programmes. Programmes in this category are TravelSmart to schools, local government, and major destinations.

\section{I. Centralised}

5.1.1. Individualised marketing. The main programme designed to deliver behaviour change on a large scale is the use of a 


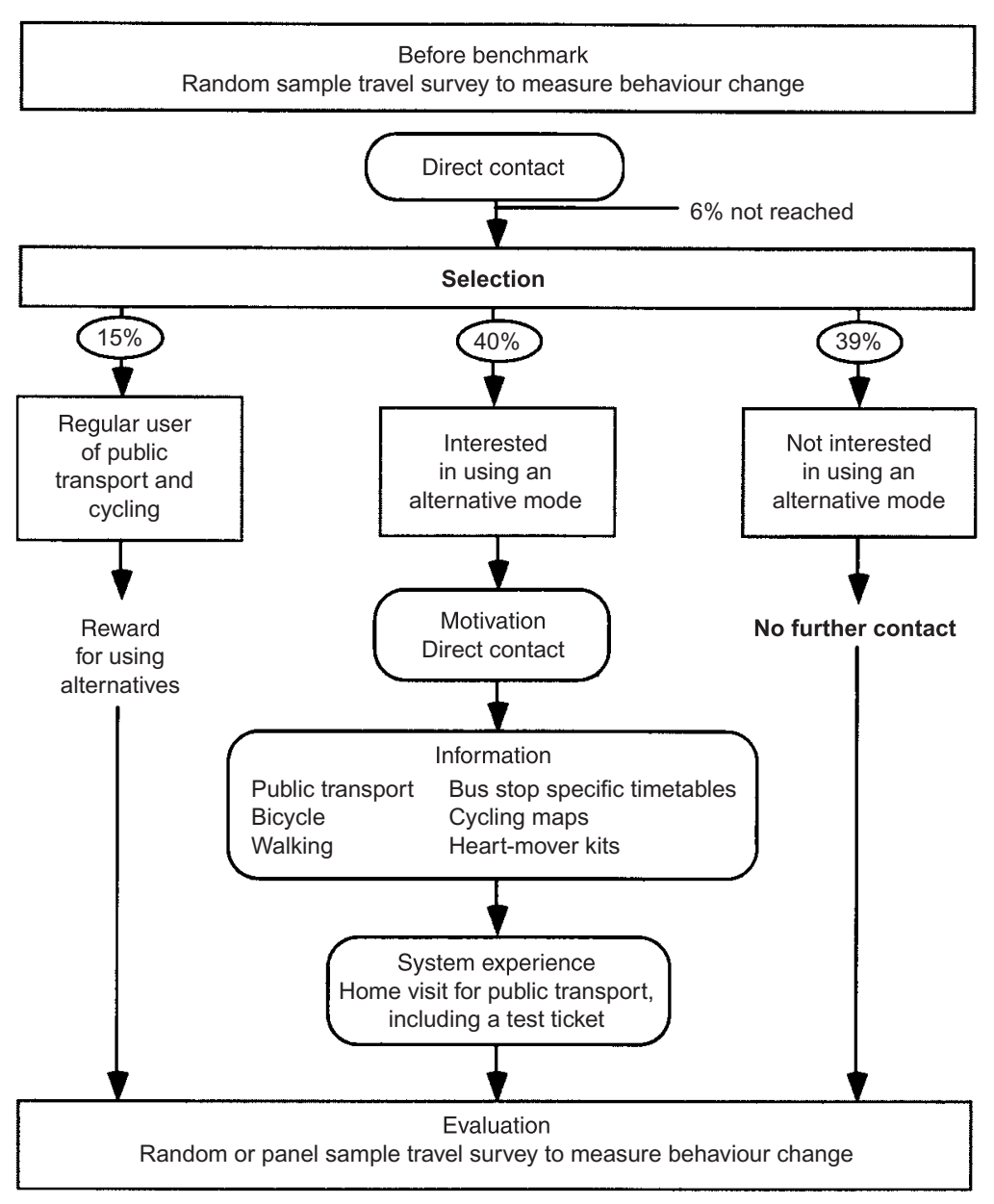

Fig. 5. Individualised Marketing process

dialogue marketing technique called Individualised Marketing. This is a customer-friendly empowerment programme that combines informing, skilling and motivating people to change some of their car trips to walking, cycling and public transport trips. Fig. 5 is an outline of how the technique works. The following description uses the results of the large-scale application.

The intervention begins by reaching all households by telephone, where it is possible to match name, telephone number and address being telephoned. In the case of the City of
South Perth, that meant 15300 out of an estimated 17300 households. Some $94 \%$ of these were reached and, through a series of questions, each household was segmented into three categories as shown in Fig. 5 and Table 1.

Households with a strong interest in using public transport but are not regular users are offered a home visit by bus drivers from the local public transport bus operator. In this circumstance, households may be offered a test ticket allowing them free use of public transport for a period of time. The principle

\begin{tabular}{|ll}
\hline Category & Attributes \\
\hline Regular user & $\begin{array}{l}\text { Already walk, cycle and use public } \\
\text { transport on a regular basis (15\%) }\end{array}$ \\
Not interested & $\begin{array}{l}\text { Not interested in using alternative modes } \\
\text { to the car (39\%) }\end{array}$ \\
Interested & $\begin{array}{l}\text { Interested in using alternative modes to the } \\
\text { car (40\%) }\end{array}$
\end{tabular}

Action

Provide requested information and a reward for their current behaviour

Leave alone. This is important as it minimises a negative response from elements of the community to the programme

These households are offered a range of information materials. For public transport it includes a local route map and pocket timetable for the bus stop nearest their house. For cycling, a series of brochures on cycling issues (e.g. cycling and the law) and a local cycling route map were offered. For walking, a 'heart movers' kit developed by the Heart Foundation was offered 


\begin{tabular}{|c|c|c|c|c|}
\hline \multirow{2}{*}{$\begin{array}{c}\text { Base } \\
\text { Sept. '97 }\end{array}$} & \multirow[b]{2}{*}{ Main mode } & \multicolumn{3}{|c|}{ After pilot test } \\
\hline & & Nov. 97 & Nov. 98 & Feb. 2000 \\
\hline $12 \%$ & Walking & $14 \%$ & $15 \%$ & $14 \%$ \\
\hline $2 \%$ & Cycling & $4 \%$ & $4 \%$ & $4 \%$ \\
\hline $60 \%$ & Car as driver & $54 \%$ & $53 \%$ & $54 \%$ \\
\hline $20 \%$ & Car passenger & $21 \%$ & $21 \%$ & $21 \%$ \\
\hline $6 \%$ & Public transport & $7 \%$ & $7 \%$ & $7 \%$ \\
\hline $3 \cdot 4$ & Trips per person per day & $3 \cdot 4$ & $3 \cdot 4$ & $3 \cdot 4$ \\
\hline$n=383$ & Sample size-households & $n=172$ & $n=206$ & $n=145$ \\
\hline
\end{tabular}

Table 2. Behaviour change achieved by the pilot test

applied is that people can also change their behaviour through experience.

On completion of the intervention and after the test tickets have expired, a random sample of households in all three segments complete a one-day travel diary. In future programmes it is planned to also use a panel sample selection to allow clearer identification of which population groups change their behaviour.

The rewards offered were a book on the history of the local authority area, a TravelSmart mug or water bottle and a carry bag for shopping.

(a) Pilot test. The pilot test showed a 10\% decrease in car driver trips through a 90\% increase in cycling trips, 20\% increase in public transport trips and a 16\% increase in walking trips. The level of mobility measured by the number of trips people made (3.4 per day) and the number of places they went to remained constant. People on average increased their daily physical activity through walking and cycling by 4 min per day. These results apply to the whole community, including those who chose not to participate in the programme.

Survey work has shown that this behaviour change was sustained two years after the pilot project was completed. The results are shown in Table 2 .

A number of control groups were used to ascertain if there were any changes in travel behaviour over the two years due to external effects. For the November 1997 'after' survey a control group with a sample size of 153 households was also surveyed. A control group with a sample size of 207 households was used for the November 1998 'after' survey. In both cases there were no external changes in travel behaviour detected. The control group samples were randomly selected from households within the City of South Perth.

The February 2000 sample raised the issue of seasonal effects. To deal with this, a previous continuous travel survey over a 12-month period in Perth was used. The only available survey of this nature was undertaken in 1986. The February 2000 results were adjusted accordingly. A control group survey was not undertaken for the February 2000 survey.

(b) First large-scale application. A large scale application of this project to the 15300 households achieved a better result than the pilot project. The large-scale results are shown in Table 3.

The town of Victoria Park is a neighbouring local government authority with a population of 26000 people. It was used as a control group as there was a previous travel survey available ${ }^{5}$ and it was removed from the effects of the Individualised Marketing programme that covered the entire population of the City of South Perth. The sample size of the 1999 Victoria Park travel survey was 426 households. A total of 242 households were drawn from the original sample to form a panel sample. The control group results are shown in Table 3 with the modal split remaining constant except for a shift in walking trips to car passenger trips.

A second 'after' survey was undertaken in November 2001 with a sample size of just under 800 households; however, the results are not yet available.

\begin{tabular}{|c|c|c|c|c|c|}
\hline \multirow{2}{*}{$\begin{array}{c}\text { Base } \\
\text { Sept. '97 }\end{array}$} & \multirow[b]{2}{*}{ Main mode } & \multicolumn{2}{|c|}{$\begin{array}{l}\text { Control group } \\
\text { Victoria Park }\end{array}$} & \multicolumn{2}{|c|}{$\begin{array}{l}\text { 'After' large-scale } \\
\text { evaluation survey }\end{array}$} \\
\hline & & Before & After & Oct. 2000 & Extent of change \\
\hline $12 \%$ & Walking & $15 \%$ & $13 \%$ & $16 \%$ & $+35 \%$ \\
\hline $2 \%$ & Cycling & $4 \%$ & $4 \%$ & $3 \%$ & $+61 \%$ \\
\hline $60 \%$ & Car as driver & $56 \%$ & $56 \%$ & $52 \%$ & $-14 \%$ \\
\hline $20 \%$ & Car passenger & $20 \%$ & $22 \%$ & $22 \%$ & $+9 \%$ \\
\hline $6 \%$ & Public transport & $5 \%$ & $5 \%$ & $7 \%$ & $+17 \%$ \\
\hline $3 \cdot 4$ & Trips per person per day & - & - & $3 \cdot 4$ & 0 \\
\hline$n=383$ & Sample size households & $n=242$ & $n=242$ & $n=706$ & - \\
\hline
\end{tabular}




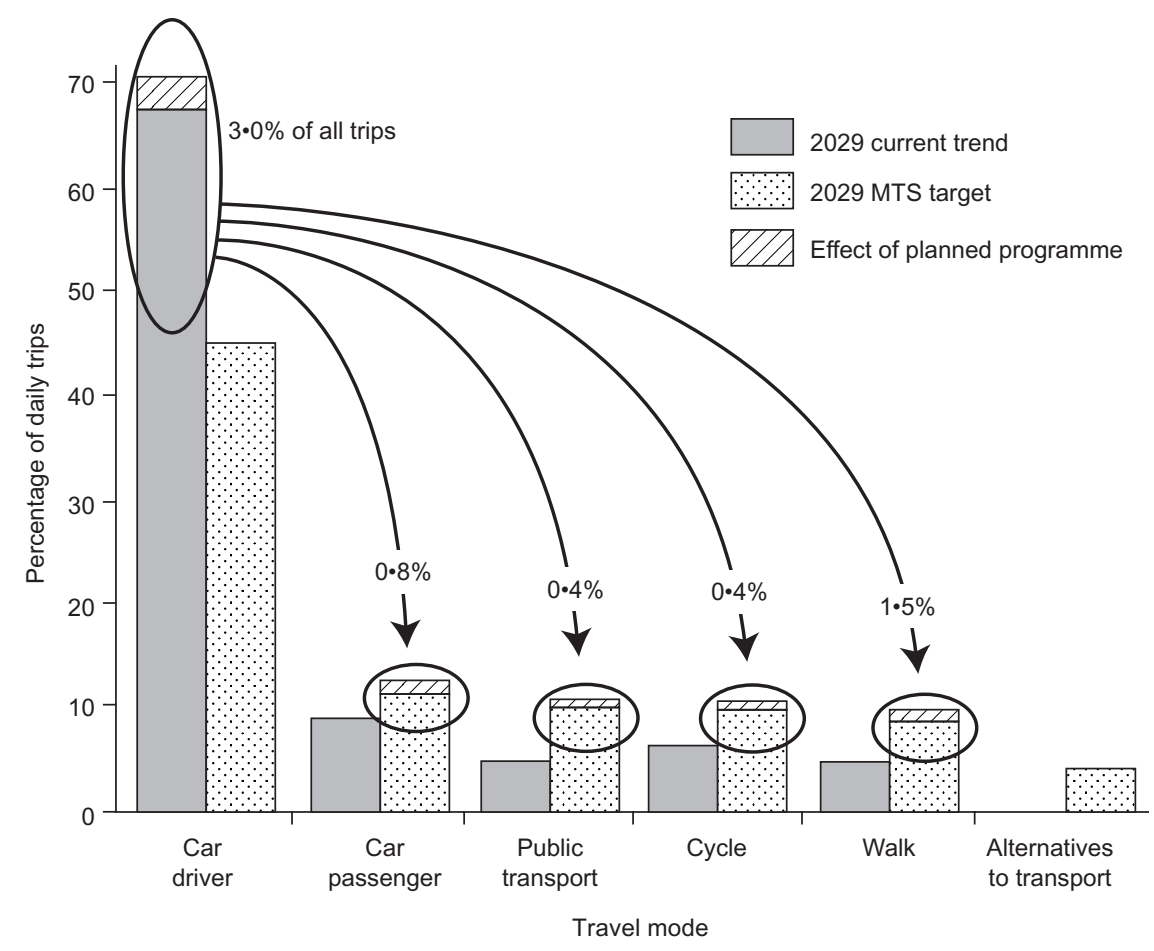

Fig. 6. Effect of large-scale application on MTS targets

The increase in public transport patronage in the City of South Perth has been confirmed with an average $24 \%$ increase in public transport initial boardings. (Initial boardings are used to measure increased fare revenue as there is no revenue gained from transfers.) This information was derived from the public transport electronic ticketing system covering sections of bus routes operating within the City of South Perth. The initial boardings for 1999 were used as the benchmark and the initial boardings for 2000 and February to June 2001 were compared against 1999 to derive this $24 \%$ increase.

The cost of implementation, including installation of bus stop specific timetable modules, is just under $\mathrm{A} \$ 38$ per person for the whole population - a total cost of $\mathrm{A} \$ 1 \cdot 3$ million. Many people argue that this is too expensive, which is true if compared to the traditional cost measure (i.e. the delivery cost of marketing materials into each household).

A socio-economic evaluation of the benefits and costs showed a 59:1 benefit-cost ratio and a net present value of $\mathrm{A} \$ 72$ million (discounted at 8\% over 15 years). The cost-benefit analysis method is outlined by Ker and James. ${ }^{6}$ The major benefits were

(a) net savings in car running costs (includes public transport fares) $=\mathrm{A} \$ 43.9$ million

(b) air pollution and greenhouse impacts $=\mathrm{A} \$ 15.6$ million

(c) health and road trauma benefits $=\mathrm{A} \$ 8.4$ million

(d) reduction in road congestion $=\mathrm{A} \$ 7$ million.

It is worth noting if net savings in car running costs only are used, the cost-benefit ratio is still very high. For example, the large-scale project cost $\mathrm{A} \$ 1.4$ million and the net car running cost savings for one year are $\mathrm{A} \$ 8.26$ million. This is based on the gross car running cost savings of $A \$ 8 \cdot 8$ million minus the increased public transport fares of A $\$ 0.54$ million. The car running costs are based on the per kilometre cost of fuel, tyres and vehicle servicing; that is $17 \cdot 2$ Australian cents per kilometre.

The expansion of the programme to other areas is projected to deliver a benefit-to-cost ratio of $34: 1$ as the cost of providing additional public transport capacity is incurred. Therefore, evaluation of the intervention as a return on investment by the State Government, rather than identifying the cheapest cost to deliver information to each household, shows that the programme delivers benefits much greater than the capital cost.

(c) Main stream large-scale application. Capital funding has been secured,* on the basis of the success of the first large-scale application, to apply the project to reach a population of about 340000 over a four-year period. The benefit-cost assessment shows that an investment of $\mathrm{A} \$ 11$ million to reach 340000 people will return over $\mathrm{A} \$ 374$ million worth of benefits over a 15-year period.

If the same changes achieved by the large-scale test are extrapolated across the Perth region to 435000 people (onethird of the region's population), the impact is as shown in Fig. 6 . It is worth noting the $A \$ 14$ million required to reach this population represents about $4 \%$ of the current annual expenditure by the State Government on new public transport and road infrastructure.

*A A2.4 million will deliver Individualised Marketing to 60000 people in 2001-2002. Capital funding forward estimates of $\mathrm{A} \$ 5 \cdot 1$ million in 2002-2003 and A \$3.1 million in 2003-2004 will reach an additional 220000 people. 
The beneficiaries of this programme are as follows.

(a) Commonwealth National Government-reductions in greenhouse gas emissions and increased level of physical activity in the community.

(b) State Government-increased public transport fare revenue, deferral of road infrastructure and increased use of cycle infrastructure, reduced vehicle emissions affecting regional air quality and reduced health costs from increased level of physical activity in the community.

(c) Local government-reduced impacts from less local traffic and increased use of pedestrian and cycle infrastructure.

(d) Private sector-increased fare revenue for private-public transport operators and increased custom for local businesses as people walk to local shops rather than drive to large shopping centres.

(e) Community-savings in travel costs, increased life expectancy from increased physical activity and better air quality, and increased opportunities for social interaction with other members of the local community through more walking.

5.1.2. TravelSmart Workplace programme. The Western Australian Department of Environmental Protection has developed and implemented a TravelSmart Workplace programme. This programme is delivering similar behaviour change rates to the Individualised Marketing. It has been delivered centrally by the Department to eight employers located in the Perth Central Area.

This programme can also be placed in the empowerment category if employers implement their own activities (e.g. green commuter plans). A challenge of the workplace programme is in identifying employers who have a broader view than their core business and are willing to help influence how their employees travel to and from work.

\subsection{Empowerment of organisations}

5.2.1. TravelSmart to school. The travel surveys undertaken for the Individualised Marketing programme show that the number of education trips is the same as the number of journey-towork trips. Comparison of travel surveys undertaken in Perth in 1986 with the Individualised Marketing 'before' and control group surveys also shows that many cycling and walking trips to school have been replaced by car trips (parents driving their children to school).

The reasons for this change are likely to be subjective as the travel distance and land-use patterns have remained constant. The outcome includes greater traffic flows around schools, increased risk of road trauma for children and a growth in travel dependency by young children.

TravelSmart to school focuses on how children travel to school by including the children themselves, teachers, parents and the relevant local authority in the programme. The 'Safe-routes-toschool' programme is an important prerequisite as it identifies safe routes for children to use and makes unsafe road crossing points safer.

5.2.2. TravelSmart and local government. Local government is seen as a vital player in travel behaviour change. It has a major role in influencing local trips, providing local transport infrastructure (e.g. cycleways) and enacting land-use planning measures. Local government also has institutional discretion to grow into new activities that meet local needs.

The TravelSmart approach with local government is built on three components.

(a) Undertake random sample travel surveys of households in each local authority involved. Examples of how this is presented into resource booklets are available from the TravelSmart website at www.travelsmart.transport.wa. gov.au.

(b) Work with the local authority to develop a TravelSmart action plan. This involves local community consultation and community learning with the travel survey information.

(c) Subsidies for the employment of local TravelSmart officers. These officers will provide a mechanism to develop and implement the action plans, continue the community learning process and influence council decision-making over a period of time.

\subsubsection{Major destinations. Major trip attractors, such as uni-} versities, are in a position to influence how their 'customers' access their sites. The impetus for change is often driven by the pressure to respond to car access by providing expensive multistorey car parking. In the case of the University of Western Australia, over $40 \%$ of students and staff live within a $30-$ minute bicycle ride of the campus. In this instance, the use of voluntary travel behaviour change measures become attractive and can be very cost-effective. This programme is in the very early days of development.

\section{SUMMARY}

This paper has provided an outline of the campaign framework used to achieve the mainstreaming of the voluntary travel behaviour change paradigm within Perth, Western Australia. The key features of the framework were proving public value, garnering community support and building capacity to deliver the programme. The paper has also shown how this new paradigm has been incorporated into the capital funding resource allocation process. The results of the flagship TravelSmart Individualised Marketing programme have been presented to provide strong evidence of the effectiveness of this programme in proving public value. The smaller programmes have also been briefly outlined.

\section{CONCLUSIONS}

TravelSmart has delivered a new transport planning approach to tackle growing traffic congestion in major cities. It has been delivered through strong research to collect evidence (public value), a campaign strategy to build community support and understanding, and building capacity to deliver TravelSmart.

The success of the Individualised Marketing component will be a major step towards achieving the MTS targets in return for a small outlay. The linkage of this programme to infrastructure funding through Strategic Asset Management has provided the 
resource opportunity to expand the programme to 340000 people. Successful delivery could lead to further expansion.

The next step in proving public value is to incorporate the Individualised Marketing programme into the models used in Perth to forecast traffic volumes on the road and public transport networks.

The current implementation of Individualised Marketing pilot projects in other cities in Australia and the UK will test the ability of the programme to replicate similar results in other locations.

\section{REFERENCES}

1. DePARTMENT OF TRANSPORT. Metropolitan Transport Strategy. Western Australian State Government, Perth, 1996.
2. LEONARD H. Proceedings of a Seminar, Perth, 22 May 2000.

3. Brög W., Erl E., FunKe S. and James B. Potential for increased public transport, cycling and walking trips. Proceedings of the 23rd Australasian Transport Research Forum, Perth, 1999, 257-302.

4. The Treasury. Strategic Asset Management: An Overview. Western Australian State Government, Perth, 1994.

5. Social Data Australia. Mobility behaviour Victoria Park. Report for the Department of Planning and Infrastructure, 1999, Western Australia.

6. KeR I. and JAmes B. Evaluating behavioural change in transport-a case study of Individualised Marketing. Proceedings of the 23rd Australasian Transport Research Forum, Perth, 1999, 703-720.

Please email, fax or post your discussion contributions to the secretary: email: kathleen.hollow@ice.org.uk; fax: +44 (0)20 7799 1325; or post to Kathleen Hollow, Journals Department, Institution of Civil Engineers, I-7 Great George Street, London SWIP 3AA. 